\title{
PEMANFAATAN VIRGIN COCONUT OIL SEBAGAI FOAMING AGENT PADA BETON RINGAN
}

\author{
Salmi Afifah ${ }^{1}$, Ria Apriana ${ }^{1}$, Aditya Widianto ${ }^{1}$, Wulan Tri Wahyuni ${ }^{{ }^{*}}$ \\ ${ }^{1}$ Departemen Kimia, Fakultas Matematika dan Ilmu Pengetahuan Alam, Institut Pertanian Bogor \\ wulantriws@apps.ipb.ac.id
}

\begin{tabular}{|l|}
\hline Artikel Info \\
\hline Diterima \\
tanggal \\
23.09 .2021 \\
Disetujui \\
publikasi \\
tanggal \\
20.10 .2021 \\
Kata kunci: \\
Asam laurat, \\
beton ringan, \\
foaming agent, \\
virgin coconut \\
oil
\end{tabular}

\section{ABSTRAK}

Foaming agent dapat disintesis dengan mereaksikan asam lemak dari minyak nabati seperti asam laurat dari virgin coconut oil (VCO) dengan alkali. Foaming agent dari asam laurat VCO berpotensi sebagai salah satu aternatif pengganti foaming agent sintetik yang sulit terdegradasi. Penelitian ini bertujuan memformulasi foaming agent berbahan dasar VCO untuk menguji efektivitas kinerja foaming agent yang dihasilkan dalam aplikasi pembuatan beton ringan. Pemisahan asam laurat dari VCO menggunakan metode saponifikasi menggunakan $\mathrm{NaOH} 3,5$ $\mathrm{N}$. Formulasi foaming agent (K-laurat) dilakukan dengan mencampurkan asam laurat dengan $\mathrm{KOH} 30 \% \mathrm{~b} / \mathrm{v}$ pada perbandingan 1:0,5. Hasil yang diperoleh menunjukkan rendemen asam laurat dari VCO adalah sebesar $69,1 \% \mathrm{v} / \mathrm{v}$ sementara foaming agent berupa K-laurat yang diperoleh adalah sebanyak 738 g. Foaming

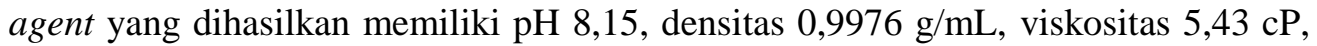
dan sudut kontak $35,81^{\circ}$. Kinerja foaming agent menunjukkan stabilitas busa sebesar 84,4-87,5\%, kemampuan pembusaan sebesar 385-533\% selama 45 menit, serta diameter busa sebesar 4,3-64,8 $\mu \mathrm{m}$. Beton ringan yang dibuat dengan foaming agent dari asam laurat VCO memiliki tekstur sedikit kasar, berpori dan mengeras setelah 1 hari. Kinerja beton ringan yang dihasilkan memiliki densitas $1497,91 \mathrm{~kg} / \mathrm{m}^{3}$ dan kuat tekan 2,8033 MPa.

\section{ABSTRACT}

Foaming agents can be synthesized by reacting fatty acids from vegetable oils such as lauric acid from virgin coconut oil (VCO) with alkali. The VCO-based foaming agent has the potency to be one of the alternative substitutes for synthetic foaming agent which is difficult to be degraded. The aim of this study was to make a VCO-based foaming agent and to evaluate the effectiveness and performance of the foaming agent in light concrete production. The separation of lauric acid from VCO was performed by the

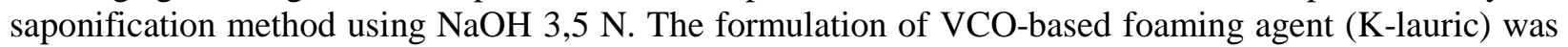
conducted by mixing the lauric acid with $\mathrm{KOH} 30 \% \mathrm{~b} / \mathrm{v}$ at a ratio of 1:0,5. The results showed that the yield of lauric acid from VCO was $69,1 \%$ (v/v) while the yield of VCO-based foaming agent (K-lauric) was $738 \mathrm{~g}$. The resulting VCO-based foaming agent has $\mathrm{pH}$ of 8,15 , density of $0,9976 \mathrm{~g} / \mathrm{mL}$, viscosity of $5,43 \mathrm{cP}$, and a contact angle of $35,81^{\circ}$. The performance of foaming agent showed foam stability of $84,4-87,5 \%$, foaming capability of $385-533 \%$ for 45 minutes, and foam diameter of $4,3-64,8 \mu \mathrm{m}$. The characteristics of light concrete produced from VCO-based foaming agent has a slightly rough morphology, porous and hardened after 1 day. The resulting light concrete performance has a density of $1497,91 \mathrm{~kg} / \mathrm{m} 3$ and a compressive strength of 2,8033 MPa.

http://dx.doi.org/10.23960/aec.v6.i2.2021.p156-167

Anal.Environ.Chem. 


\section{PENDAHULUAN}

Kebutuhan beton ringan di Indonesia dalam berbagai aplikasi teknologi konstruksi meningkat dengan pesat. Beton ringan adalah beton yang mempunyai bahan baku utama terdiri atas semen, agregat (pasir), air, dan ditambah dengan suatu bahan pengembang (foaming agent) (Jumiati dan Masthura, 2018). Foaming agent pada beton ringan ditujukan untuk membentuk gelembung udara sehingga akan menghasilkan pori-pori yang dapat menurunkan bobot jenis beton (Triastuti et al., 2017). Oleh karena itu, dapat mengurangi penggunaan semen dan pasir. Hal ini memberikan solusi ekonomis pada bisnis konstruksi karena dengan berkurangnya berat jenis beton menyebabkan berkurangnya beban yang ditanggung pondasi bangunan pada bangunan bertingkat. Berkurangnya beban bangunan dapat mengubah pondasi bangunan, mengurangi beban pekerja, dan transportasi (Amran et al., 2015).

Foaming agent yang umum digunakan berbasis poliol yang dapat menimbulkan pencemaran terhadap lingkungan dan limbahnya sulit terdegradasi (Krol et al., 2012). Menurut Rivai et al., (2017), foaming agent berbasis minyak nabati memiliki karakteristik seperti foaming agent sintetik tersebut, tetapi lebih ramah lingkungan. Salah satu bahan alami yang berpotensi untuk dikembangkan sebagai bahan baku foaming agent berbasis minyak nabati adalah virgin coconut oil (VCO). Kandungan yang paling banyak pada VCO berdasarkan SNI 7381:2008 adalah asam laurat. Basa yang direaksikan dengan asam laurat akan menghasilkan alkali-laurat yang merupakan foaming agent ramah lingkungan dan memiliki kestabilan paling baik (Kurniasih et al., 2017). Oleh karena itu, penelitian ini bertujuan memformulasi foaming agent berbahan dasar VCO untuk menguji efektivitas kinerja foaming agent yang dihasilkan dalam aplikasi pembuatan beton ringan.

\section{METODE}

\section{Alat dan Bahan}

Alat-alat yang digunakan meliputi peralatan gelas, hotplate, penangas air, termometer, pompa vakum, timbangan, kain blacu, sonikator, mixer, $\mathrm{pH}$ meter, piknometer, viskometer Brookfield LV DV-E, Contact Angel Pheonix 300, ayakan pasir 0,3 mm, Universal Testing Machine (UTM), dan cetakan beton ringan. Bahan-bahan yang digunakan terdiri atas VCO, 
$\mathrm{NaOH}$ 3,5 N, HCl, KOH, foaming agent komersial (ADT), asam laurat komersial, semen, pasir, dan akuades.

\section{Prosedur}

\section{Pemisahan Asam Laurat dari VCO (Modifikasi Pratiwi et al., 2018)}

Sebanyak $100 \mathrm{~mL}$ VCO dipanaskan dengan hotplate atau penangas air sampai suhu $70{ }^{\circ} \mathrm{C}$. Larutan $\mathrm{NaOH}$ 3,5 N sebanyak $140 \mathrm{~mL}$ dimasukkan ke dalam VCO sambil dipanaskan dan diaduk dengan suhu dijaga konstan $65-75^{\circ} \mathrm{C}$ sampai terbentuk dua lapisan. Kedua lapisan dipisahkan dengan penyaringan gravimetri. Lapisan yang akan digunakan merupakan sabun. Sebanyak $100 \mathrm{~mL} \mathrm{HCl} \mathrm{10 \%} \mathrm{dimasukkan} \mathrm{ke} \mathrm{dalam} \mathrm{sabun.} \mathrm{Campuran} \mathrm{disonikasi} \mathrm{atau} \mathrm{diaduk}$ sampai terbentuk dua lapisan cairan, lalu diambil lapisan teratasnya.

\section{Pembuatan Foaming Agent dari VCO (Modifikasi Pradesi et al., 2017)}

Sintesis ini diberikan dua perlakuan yang berbeda, yaitu dari asam laurat VCO dan asam laurat komersial. Proses diawali dengan 200,3 g asam laurat dipanaskan dengan hotplate atau penangas air, lalu diaduk hingga $65^{\circ} \mathrm{C}$. Setelah mencapai $65^{\circ} \mathrm{C}$, sebanyak $65,45 \mathrm{~mL} \mathrm{KOH} 30 \%$ (\%b/v) ditambahkan. Campuran diaduk selama 90 menit hingga homogen. Proses ini dilakukan 3 kali ulangan.

\section{Analisis Sifat Fisikokimia}

Sifat fisikokimia yang dianalisis pada foaming agent asam laurat VCO, foaming agent asam laurat komersial, dan foaming agent ADT adalah uji pH konsentrasi masing-masing 2,5\% dengan test-kit indikator $\mathrm{pH}$ universal, densitas dengan piknometer didasarkan pada SNI 01-2891-1992 poin 17.2, viskositas dengan viskometer Brookfield LV DV-E didasarkan pada Brookfield Digital Viscometer Model DV-E Operating Instructions Manual No M98-350-J0912 dengan 12 rpm dan suhu $27{ }^{\circ} \mathrm{C}$, dan sudut kontak dengan Contact Angle Analyzer Phoenix 300 didasarkan pada metode Pheonix: SBRC 2013.

\section{Pengujian Kinerja Foaming Agent (Lubis, 2019)}

\section{Pengujian Stabilitas Busa dan Kemampuan Pembusaan}

Sebanyak 0,75 g sampel foaming agent diencerkan dengan $30 \mathrm{~mL}$ akuades pada gelas ukur dan diaduk dengan homogenizer selama 15 menit. Campuran diamati volume busanya pada 
menit ke-0, ke-15, ke-30 dan ke-45. Stabilitas dan kemampuan pembusaaan dihitung dengan persamaan berikut ini:

\section{Pengukuran Diameter Busa}

$$
\begin{gathered}
\text { Stabilitas busa }(\%)=\frac{\text { Tinggi busa akhir }}{\text { Tinggi busa awal }} \times 100 \% \\
\text { Kemampuan pembusaaan }(\%)=\frac{\text { Tinggi busa }}{\text { Tinggi air }} \times 100 \%
\end{gathered}
$$

Sebanyak $0,75 \mathrm{~g}$ sampel foaming agent diencerkan dengan $30 \mathrm{~mL}$ akuades dan diaduk dengan homogenizer selama 15 menit. Campuran tersebut dikocok dengan vortex selama 5 menit. Busa yang dihasilkan diambil lalu diletakkan pada kaca preparat lalu dilihat dan diukur dengan mikroskop dengan perbesaran 40 kali.

\section{Pembuatan Beton Ringan (Modifikasi Lubis, 2019)}

Sebanyak 2,05 kg semen, 2,34 kg pasir, 0,92 L air, dan 2,16 L busa (40\% dari jumlah semua bahan campuran) dicampurkan. Busa diperoleh dari $25 \%$ foaming agent dan $75 \%$ air yang diaduk dengan kecepatan tinggi melalui hand blender hingga membentuk busa yang kaku. Setelah itu, campuran dicetak berbentuk kubus berukuran $15 \times 15 \times 15 \mathrm{~cm}$. Beton ringan yang dihasilkan kemudian dikeringkan dan disimpan sampai pengujian kinerja beton ringan.

\section{Pengujian Kinerja Beton Ringan (Lubis, 2019)}

Pengujian kinerja beton ringan terdiri atas pengujian densitas dan uji kuat tekan. Pengujian densitas $\left(\mathrm{kg} / \mathrm{m}^{3}\right)$ beton ringan diawali dengan massa dan volume beton ditentukan dengan membagi massa dan volume sesuai umur penyimpanan. Beton ringan yang diuji pada uji kuat tekan dengan Universal Testing Machine (UTM) adalah sampel yang telah didiamkan selama 14 dan 21 hari. Kemudian, beton diuji dengan menggunakan alat penekan hingga hancur. Beban maksimum dicatat dan dihitung dengan rumus:

$$
f_{c}=\frac{P}{A}
$$

Keterangan :

$f c=$ kuat tekan beton (MPa)

$\mathrm{P}=$ beban maksimum $(\mathrm{N})$

$\mathrm{A}=$ luas penampang benda uji $\left(\mathrm{mm}^{2}\right)$ 


\section{HASIL DAN PEMBAHASAN}

\section{Asam Laurat Hasil Pemisahan dari Virgin Coconut Oil (VCO)}

Pemisahan asam laurat dari VCO dilakukan menggunakan metode saponifikasi. Pemisahan tersebut menghasilkan dua lapisan, yaitu lapisan atas berupa padatan sabun dan lapisan bawah berupa cairan gliserol, kedua lapisan tersebut dapat dipisahkan dengan penyaringan vakum (Pratiwi et al., 2018). Alternatif lain untuk memisahkan sabun yang diperoleh dari gliserol adalah dengan penyaringan gravimetri. Sabun yang didapatkan dari 1,1 L VCO adalah sebanyak $1209 \mathrm{~g}$, reaksi yan terjadi disajikan pada persamaan (1).<smiles>[R]C(=O)OCC([R])[R]([R])([R])[H]</smiles>

$\mathrm{R}:\left(\mathrm{CH}_{2}\right) 10 \mathrm{CH} 3$

Tahap selanjutnya sabun yang diperoleh diasamkan dengan $\mathrm{HCl} 10 \%$ untuk melepaskan asam lemaknya (persamaan 2). Sabun pada tahap ini tidak cepat bereaksi dengan $\mathrm{HCl}$ sehingga perlu diberikan perlakuan fisik, salah satunya dengan pemberian gelombang ultrasonik (Sari et al., 2018). Menurut Sari et al., (2018), pemisahan asam laurat dengan memanfaatkan gelombang ultrasonik akan menggetarkan partikel dalam medium hingga bisa memecah ikatan antar molekul dan mempercepat terjadinya reaksi. Hasil yang diperoleh dari reaksi ini berupa dua lapisan, yaitu lapisan atas berupa cairan asam lemak dan lapisan bawah berupa cairan $\mathrm{NaCl}$. Hasil ini sesuai dengan yang dilaporkan oleh Pratiwi et al. (2018). Asam lemak yang didapatkan dari $1209 \mathrm{~g}$ sabun adalah $681 \mathrm{~mL}$, dengan rendemen 69,1\% (\%v/v).

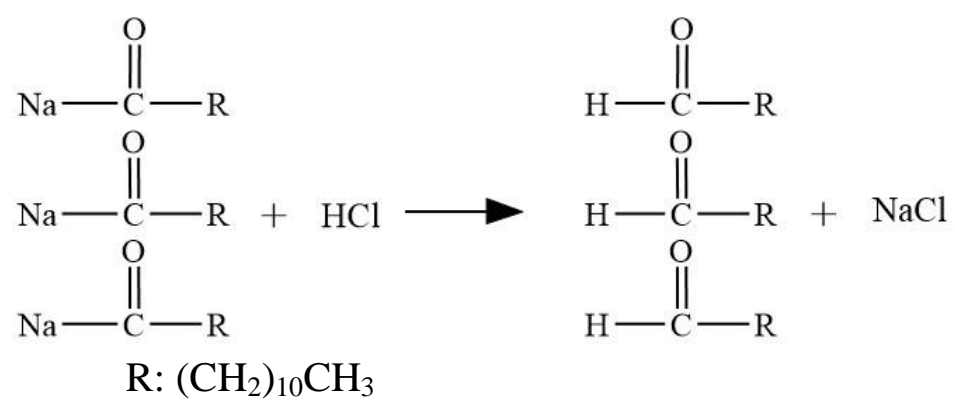

http://dx.doi.org/10.23960/aec.v6.i2.2021.p156-167

Anal.Environ.Chem. 


\section{Foaming Agent dari Asam Laurat VCO}

Pembuatan foaming agent dari asam laurat VCO dilakukan dengan metode saponifikasi. Alkali yang digunakan pada pembuatan foaming agent ini ialah $\mathrm{KOH}$ sehingga didapat sabun yang cair/lunak (Widiyati dan Wahyuningtyas, 2020). Perbandingan asam laurat dan alkali KOH yang digunakan ialah 1:0,5 karena menurut Pradesi et al., (2017) perbandingan tersebut menghasilkan foaming agent dengan karakter terbaik. Tabel 1 menunjukkan jumlah foaming agent yang diperoleh dari asam laurat VCO dan asam laurat komersial yang digunakan sebagai pembanding.

Tabel 1. Jumlah foaming agent yang diperoleh dengan metode saponifikasi

\begin{tabular}{lc}
\hline \multicolumn{1}{c}{ Sumber Asam Laurat } & Jumlah Foaming Agent Yang Diperoleh $(\mathrm{g})$ \\
\hline Virgin Coconut Oil $(\mathrm{VCO})$ & 738 \\
Komersial & 791 \\
\hline
\end{tabular}

Jumlah foaming agent dari asam laurat komersial lebih banyak dibandingkan foaming agent dari asam laurat VCO. Hal ini diduga terjadi akibat kondisi asam laurat berbeda. Asam laurat VCO berbentuk cairan sehingga diduga masih mengandung air sementara asam laurat komersial berupa padatan kering. Foaming agent dari asam laurat VCO memiliki bentuk fisik menyerupai pasta. Sementara itu, foaming agent dari asam laurat komersial yang dihasilkan memiliki bentuk fisik berupa padatan berwarna putih. Jumlah $\mathrm{KOH}$ yang ditambahkan memengaruhi bentuk dari sabun yang dihasilkan. Konsentrasi $\mathrm{KOH}$ yang tinggi menghasilkan sabun yang lebih padat (Susanti dan Guterres, 2018).

\section{Sifat Fisikokimia Foaming Agent}

Nilai $\mathrm{pH}$ foaming agent dari asam laurat VCO dan foaming agent dari asam laurat komersial bersifat sedikit basa (Tabel 2). Hal ini terjadi karena adanya penambahan $\mathrm{KOH}$ pada tahap saponifikasi. Foaming agent yang baik dalam pembuatan beton ringan dalam mendekati keadaan netral $( \pm 7)$ karena lebih mudah pengaplikasian dalam bidang konstruksi. Contohnya, ketika $\mathrm{pH}$ bersifat asam maka akan merusak besi pada pengaplikasian beton berkolom.

Hasil densitas dan viskositas yang diperoleh menunjukkan hasil foaming agent ADT berbeda dengan foaming agent lain (Tabel 2). Peningkatan densitas akan meningkatkan viskositas. Semakin besar nilai viskositasnya maka semakin baik stabilitas pembusaan yang 
dihasilkan. Penipisan lapisan busa dapat dipengaruhi akibat gaya kohesi yang terlalu besar dibandingkan gaya adhesi sehingga membuat viskositasnya berkurang. Suhu terlalu tinggi juga dapat berpengaruh pelemahan ikatan molekul serta mendekomposisi pemutusan ikatan molekul. Hal ini dapat mengurangi kerapatan massa sehingga memengaruhi penurunan viskositas.

Tabel 2. Hasil uji sifat fisikokimia foaming agent

\begin{tabular}{ccccc}
\hline Jenis foaming agent & $\mathbf{p H}$ & Densitas $(\mathbf{g} / \mathbf{m L})$ & Viskositas $(\mathbf{c P})$ & Sudut kontak $\left.\mathbf{(}^{\mathbf{9}}\right)$ \\
\hline Asam laurat VCO & $8,15 \pm 0,00$ & $0,9976 \pm 0,0000$ & $5,43 \pm 0,02$ & $35,81 \pm 0,31$ \\
\hline Asam laurat komersial & $7,66 \pm 0,01$ & $0,9983 \pm 0,0000$ & $4,53 \pm 0,02$ & $38,52 \pm 0,22$ \\
\hline Komersial ADT & $2,14 \pm 0,00$ & $1,0200 \pm 0,0000$ & $1726 \pm 0,00$ & $26,21 \pm 0,06$ \\
\hline
\end{tabular}

Hasil uji sudut kontak dengan nilai terendah diperoleh foaming agent ADT (Tabel 2). Gaya adhesi antar partikel yang terjadi pada foaming agent ADT cenderung lebih besar daripada gaya kohesinya, sehingga sudut kontak antara medium pengukuran dengan zat cair akan saling menempel dan nilai sudut kontak menjadi lebih kecil. Semakin kecil sudut kontaknya, semakin bagus kinerjanya (Pradesi et al., 2017). Sudut kontak yang lebih kecil juga dipengaruhi akibat semakin berkurangnya tegangan permukaan.

\section{Kinerja Foaming Agent dari Asam Laurat VCO dan Komersial Stabilitas Busa dan Kemampuan Pembusaan}

Hasil uji stabilitas foaming agent untuk beton ringan dalam selang waktu 15, 30, dan 45 menit ditunjukkan pada Gambar 1. Foaming agent dari asam laurat VCO, asam laurat komersial, dan foaming agent komersial (ADT) mengalami penurunan stabilitas busa yang berbeda. Foaming agent dari asam laurat komersial mengalami laju penurunan paling besar, sementara foaming agent dari asam laurat VCO dan foaming agent ADT relatif dapat mempertahankan stabilitas busanya. Penurunan nilai stabilitas busa tersebut menunjukkan bahwa terdapat gelembung yang pecah setelah waktu tertentu. Foaming agent yang baik akan menghasilkan stabilitas busa yang tinggi (Lubis, 2019). Foaming agent ADT memiliki stabilitas busa tertinggi diikuti foaming agent dari asam laurat VCO.

http://dx.doi.org/10.23960/aec.v6.i2.2021.p156-167

Anal.Environ.Chem. 


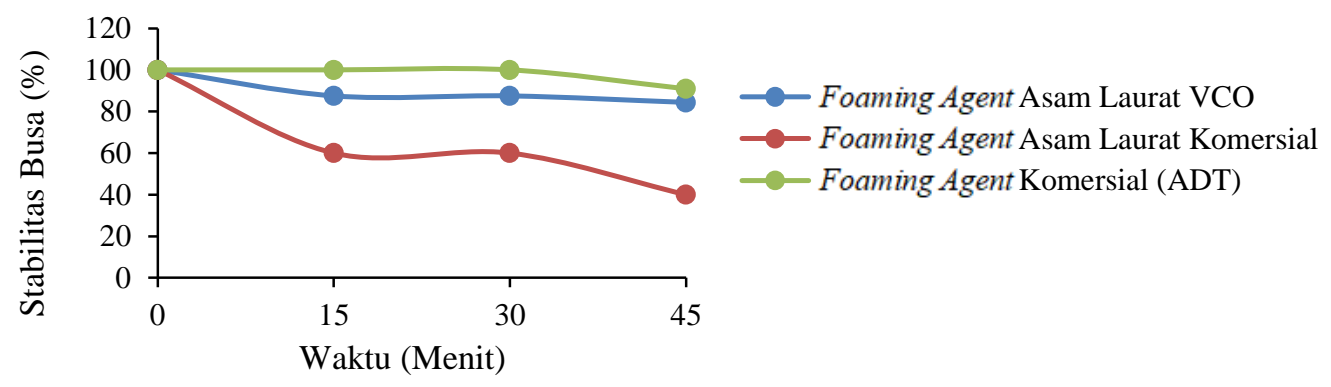

\section{Gambar 1. Stabilitas busa foaming agent}

Hasil uji kemampuan pembusaan foaming agent untuk beton ringan dalam selang waktu 15, 30, dan 45 menit ditunjukkan pada Gambar 2. Kemampuan busa mengalami penurunan seiring bertambahnya waktu. Penurunan kemampuan pembusaan dari menit ke-0 hingga menit ke-15 menunjukkan busa yang dibentuk pada awal pengujian telah pecah. Foaming agent yang baik dapat menghasilkan busa yang banyak. Kemampuan busa dari yang tertinggi adalah foaming agent dari asam laurat VCO, foaming agent ADT, dan foaming agent dari asam laurat komersial. Kemampuan busa yang rendah dapat disebabkan pengocokan yang kurang sempurna (Yuliyanti et al., 2019).

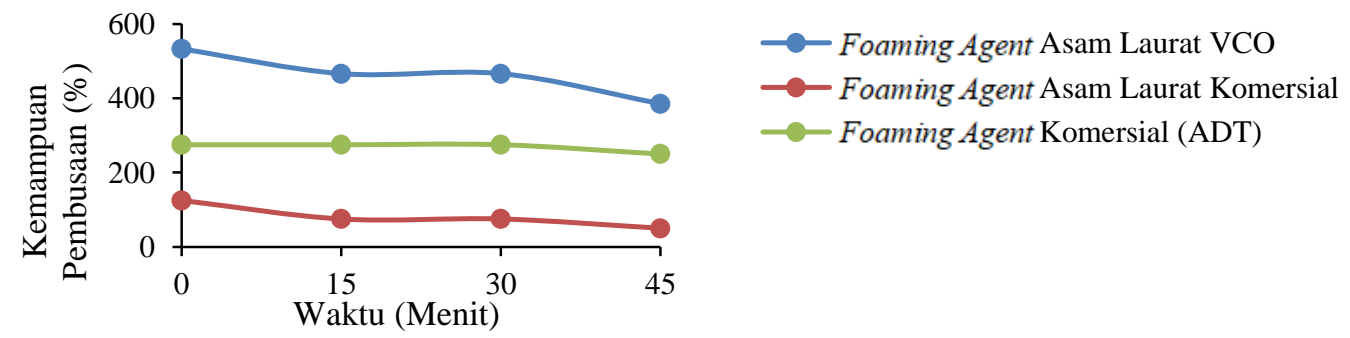

Gambar 2. Kemampuan pembusaan foaming agent

\section{Diameter Busa}

Hasil pengukuran diameter busa ditunjukkan pada Gambar 3. Busa yang dihasilkan foaming agent dari asam laurat VCO memiliki gelembung busa berbentuk bulat dengan diameter 4,3-64,8 $\mu \mathrm{m}$ (Gambar 3a). Busa yang dihasilkan foaming agent asam laurat komersial memiliki gelembung busa berbentuk bulat tak beraturan dengan diameter 2,6-27,6 $\mu \mathrm{m}$ (Gambar 3b). Busa yang dihasilkan foaming agent ADT memiliki gelembung busa berbentuk bulat tak beraturan dengan diameter 2,1-66,1 $\mu \mathrm{m}$ (Gambar 3c). Semua perlakuan foaming agent memiliki diameter kurang dari $1 \mathrm{~mm}$. Hal ini menunjukkan busa dapat digunakan pada pembuatan beton ringan. 
Diameter busa yang memiliki ukuran lebih dari $1 \mathrm{~mm}$ akan meningkatkan nilai porositas pada beton ringan sehingga akan menghasilkan beton yang tidak kuat (Lubis, 2019).
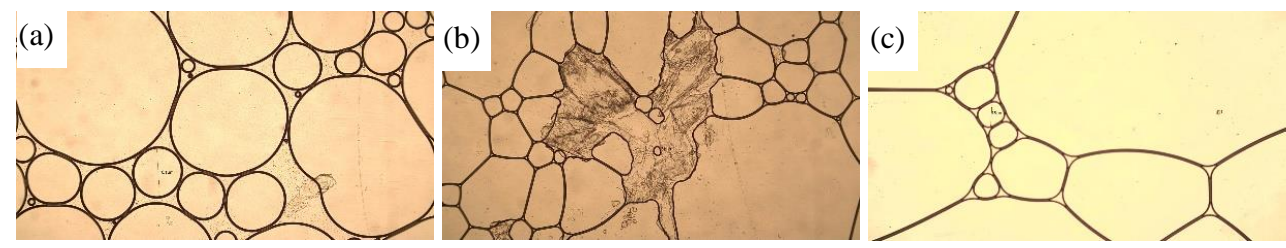

\section{Gambar 3. Diameter busa dari foaming agent (a) asam laurat VCO, (b) asam laurat komersial, dan (c) ADT}

\section{Hasil Pembuatan Beton Ringan}

Campuran pada beton ringan menggunakan foaming agent dari asam laurat VCO dan asam laurat komersial memiliki tekstur lembut, terdapat gelembung, sedikit cair, dan mengeras setelah 1 hari. Campuran tersebut ditambahkan $500 \mathrm{~mL}$ air dari takaran yang sudah ditetapkan karena campuran masih sangat keras dan menggumpal. Beton ringan yang telah mengeras memiliki tekstur kasar (Gambar 4a). Campuran pada beton ringan menggunakan foaming agent asam laurat komersial memiliki tekstur lembut, terdapat gelembung, tidak terlalu cair, dan mengeras setelah 1 hari. Campuran ditambahkan $1000 \mathrm{~mL}$ air karena campuran masih sangat keras dan kering. Beton ringan yang telah mengeras memiliki tekstur agak kasar (Gambar 4b). Perbedaan jumlah air yang ditambahkan disebabkan pasir yang digunakan tidak direndam sehingga saat pencampuran air lebih banyak terserap oleh pasir tersebut.
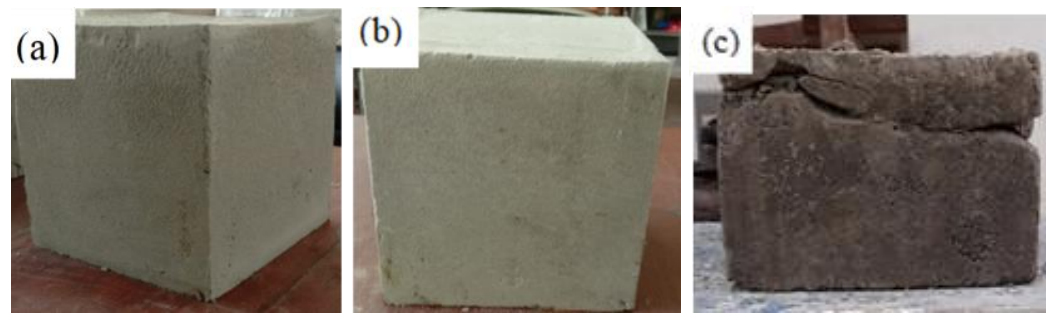

\section{Gambar 4. Beton ringan setelah 1 hari pembuatan dengan menggunakan foaming agent dari (a) asam laurat VCO dan (b) asam laurat komersial, dan (c) ADT}

Campuran pada beton ringan dengan menggunakan foaming agent ADT memiliki tekstur lembut, terdapat gelembung dan sangat cair, tidak ada penambahan air serta mengeras setelah 14 hari dengan tekstur kasar dan berpori (Gambar 4c). Beton ringan yang telah mengeras tersebut 
patah ketika dilepaskan dari cetakan karena masih belum terlalu kering. Waktu yang dibutuhkan beton ringan dari foaming agent ADT lebih lama karena campuran beton ringan sangat cair dan busa yang dihasilkan sedikit.

\section{Hasil Pengujian Kinerja Beton Ringan}

Berdasarkan SNI 03-3449-2002, hasil pengujian seluruh sampel dapat diklasifikasikan sebagai beton ringan karena memiliki densitas $<1900 \mathrm{~kg} / \mathrm{m}^{3}$. Densitas beton ringan menurun seiring bertambahnya usia penyimpanan (Tabel 3). Hal ini terjadi karena beton akan mengalami pengeringan sempurna pada hari ke-28. Densitas beton ringan dari foaming agent asam laurat VCO setara dengan beton ringan foaming agent asam laurat komersial sementara densitas beton ringan foaming agent komersial lebih besar. Hal ini disebabkan banyaknya jumlah pori-pori pada beton asam laurat VCO dan komersial sehingga bobot beton menjadi lebih ringan.

Tabel 3. Hasil uji densitas beton ringan

\begin{tabular}{lcc}
\hline \multicolumn{1}{c}{ Beton ringan } & \multicolumn{2}{c}{ Densitas $\left(\mathbf{K g} / \mathbf{m}^{\mathbf{3}}\right)$} \\
\cline { 2 - 3 } & Hari 7 & Hari 14 \\
\hline Foaming agent asam laurat VCO & 1499,95 & 1497,91 \\
Foaming agent asam laurat komersial & 1437,75 & 1434,36 \\
Foaming agent ADT & 1859,11 & 1757,48 \\
\hline
\end{tabular}

Tabel 4. Hasil uji kuat tekan beton ringan

\begin{tabular}{lccc}
\hline \multicolumn{1}{c}{ Beton Ringan } & $\begin{array}{c}\text { Beban maksimum } \\
\text { setelah kalibrasi (kN) }\end{array}$ & $\begin{array}{c}\text { Kuat tekan percobaan } \\
\text { hari ke-14 dan 21 }\end{array}$ & $\begin{array}{c}\text { Kuat tekan perkiraan } \\
\text { hari ke-28 }\end{array}$ \\
\hline Foaming agent asam laurat VCO & 54,8971 & $2,4669^{*}$ & 2,8033 \\
Foaming agent asam laurat komersial & 39,3758 & $1,8001^{*}$ & 2,0456 \\
Foaming agent ADT & 87,3996 & $3,8767^{* *}$ & 4,0807 \\
\hline
\end{tabular}

*Kuat tekan hari ke-14, ${ }^{* *}$ Kuat tekan hari ke-21

Kuat tekan beton ringan sebanding dengan penurunan densitasnya (Tabel 4). Kuat tekan beton ringan pada hari ke-28 dapat diperkirakan dengan nisbah kuat tekan berdasarkan PBI N.I.21971 dan SNI 03-2834-2000. Semakin bertambahnya umur beton ringan, semakin meningkat kuat tekannya. Kuat tekan beton ringan foaming agent asam laurat VCO memiliki lebih tinggi dibandingkan beton foaming agent asam laurat komesial. Berdasarkan SNI 03-3449-2002, kuat tekan beton ringan dengan jenis struktural ringan adalah 6,89-17,24 $\mathrm{MPa}$. Ketiga beton ringan

http://dx.doi.org/10.23960/aec.v6.i2.2021.p156-167 
yang dihasilkan memiliki kuat tekan rendah, diduga karena menggunakan agregat yang tidak dijenuhkan terlebih dahulu dan ukuran agregat yang sangat kecil.

\section{KESIMPULAN}

Formulasi foaming agent dari asam laurat VCO memiliki potensi besar sebagai alternatif pengganti foaming agent sintetik dan sebagai bahan dalam pembuatan beton ringan. Foaming agent VCO memiliki kemampuan dan stabilitas busa serta kuat tekan yang lebih baik dibandingkan foaming agent asam laurat komersial. Namun, kuat tekan yang didapatkan masih berada dibawah standar SNI sehingga perlu dilakukan studi lebih lanjut untuk meningkatkan performanya sebagai foaming agent beton ringan.

\section{UCAPAN TERIMA KASIH}

Ucapan terima kasih kepada Kementerian Pendidikan, Kebudayaan, Riset, dan Teknologi Republik Indonesia yang telah membiayai penelitian ini melalui skema PKM-R.

\section{DAFTAR PUSTAKA}

Amran, Y.H., Mugahed, Farzadnia, N., Dan Ali A.,A., 2015, Properties And Applications Of Foamed Concrete; A Review, Construction And Building Materials., 101: 990 - 1005.

[Dpu] Departemen Pekerjaan Umum, 1971, Peraturan Beton Bertulang Indonesia, Direktorat Penyelidikan Masalah Bangunan., Bandung.

Jumiati, E., dan Masthura, 2018, Pembuatan Beton Ringan Berbasis Sampah Organik, Jurnal Ilmu Fisika dan Teknologi, 2(1): 15 - 22.

Krol, B., Prochaska, K., dan Chrzanowski, L., 2012, Biodegradability of Firefighting Foams, Fire Technology., 48: 173 - 178.

Kurniasih, E. Fransiska, H. Reihan, L. dan Fadhilah, R., 2017, Sintesa Surfaktan Non Ionik Coco Dilaurilamida Melalui Reaksi Ester Amidasi Enzimatis, Journal of Science and Technology., 15(1): 35 - 40.

Lubis, M., 2019, Formulasi Foaming Agent dari Minyak Sawit untuk Aplikasi pada Beton Ringan, Tesis, Fakultas Teknologi Pertanian, Institut Pertanian Bogor, Bogor.

Pradesi, J., 2018, Sintesis dan Karakterisasi Sifat Fisikokimia Foaming Agent dari Asam Lemak Sawit, Tesis, Fakultas Teknologi Pertanian, Institut Pertanian Bogor, Bogor.

http://dx.doi.org/10.23960/aec.v6.i2.2021.p156-167 
Pradesi, J., Hambali, E., dan Warsiki, E., 2017, Sintesis Foaming Agent Asam Laurat Sawit dan Karakteristik Sifat Fisikokimia, Jurnal Teknologi Industri Pertanian., 27(3): 291 - 297.

Pratiwi, I., Pardi, dan Yunus, M., 2018, Pemisahan Asam Laurat dari Virgin Coconut Oil (VCO) dengan Metode Saponifikasi dan Sonikasi. Prosiding Seminar Nasional Politeknik Negeri Lhokseumawe, 1 September 2018, Lhokseumawe, Indonesia, 235 - 239.

Rivai, M., Hambali, E., Suryani, A., Fitria, R., Firmansyah, S., dan Pradesi, J, 2017, Synthesis of Palm Oil Fatty Acid as Foaming Agent for Firefighting Application, IOP Conference Series: Earth And Environmental Science., 65: 1 - 11.

[SNI] Standar Nasional Indonesia, 2000, Tata Cara Pembuatan Rencana Beton Normal, Badan Standardisasi Nasional Indonesia, Bandung, Indonesia.

[SNI] Standar Nasional Indonesia, 2002, Tata Cara Rencana Pembuatan Campuran Beton dengan Agregat Ringan, Badan Standardisasi Nasional Indonesia, Bandung, Indonesia.

[SNI] Standar Nasional Indonesia, 2008, Minyak Kelapa Virgin (VCO), Badan Standardisasi Nasional, Jakarta, Indonesia.

Sari, I., Pardi, dan Nahar, 2018, Pemisahan Asam Laurat dari Minyak Inti Sawit dengan Metode Saponifikasi dan Sonikasi, Prosiding Seminar Nasional Politeknik Negeri Lhokseumawe, 1 September 2018, Lhokseumawe, Indonesia, 96 - 100.

Susanti, M.M., dan Guterres, A.D.A., 2018, Pengaruh Penambahan Kalium Hidroksida (KOH) terhadap Mutu Sabun Lunak Berbahan Dasar Minyak Goreng Bekas, Medsains, 4(1): 25 33.

Triastuti, Nugroho, A., dan Rahman, A, 2017, Pemanfaatan Abu Ampas Tebu dalam Pembuatan Beton Busa Ringan, Jurnal Permukiman, 12(1): 20 - 24.

Widiyati, D.W., dan Wahyuningtyas, D, 2020, Optimasi Pemanfaatan Minyak Serai (Cyimbopogancitrates DC) sebagai Zat Antiseptik pada Pembuatan Sabun Lunak Herbal, Jurnal Inovasi Proses, 5(1): 1 - 8.

Yuliyanti M, Husada, V.M.S., Fahrudi, H.A.A.F, dan Setyowati, W.A.E., 2019, Optimasi Mutu dan Daya Detergensi Sediaan Detergen Cair Ekstrak Biji Mahoni (Swietenia Mahagoni), Jurnal Kimia dan Pendidikan Kimia, 4(2): 65 - 76. 